The Open Mechanical Engineering
Bentham open
CrossMark
Content list available at: www.benthamopen.com/TOMEJ/
DOI: $10.2174 / 1874155 \mathrm{X} 0161001000 \mathrm{C}$

\title{
Parametric Analysis of a Passive Energy Management Through Increased Thermal Capacitance
}

\author{
Joseph Carpenter, Pedro J. Mago ${ }^{*}$, Rogelio Luck and Heejin Cho \\ Department of Mechanical Engineering, Mississippi State University, Mississippi State, MS 39762, USA
}

\begin{abstract}
This paper evaluates the influence of several parameters on the potential of using increased thermal capacitance (ITC) as a passive energy management technique to decrease a building's cooling load. ITC is implemented by circulating water from a storage tank through a piping system located in the building's ceiling. The cooling load of the ITC enhanced building is compared to the cooling load of a reference building without ITC. TRNSYS, a transient system simulation software, is used to simulate both the ITC enhanced building and the reference building. The following parameters that affect the performance of the ITC are analyzed: tank size, specific heat, mass flow rate, initial temperature of the working fluid, pipe material and wall thickness, and location of the piping system in the ceiling. These parameters are also modified to achieve the best results for each of the climate conditions investigated. The simulations demonstrate that ITC has the potential to reduce the overall cooling load in a range between $4 \%$ to $8 \%$, depending on the location and the month of the year.
\end{abstract}

Keywords: Cooling load reduction, Increased thermal capacitance, Passive energy management, Parametric analysis.

\section{INTRODUCTION}

About $40 \%$ [1] of the current energy usage in buildings is due to heating and cooling systems. One way to reduce energy usage in buildings is to reduce the energy load using active and/or passive systems.Along with increased interests in the demand side energy management [2 - 4] to save costs in energy generation and plant construction and increase grid resilience, many studies have been conducted to reduce/shift peak load in buildings (e.g., [5 - 9]). Lee and Braun [5] proposed a model-based approach to minimize peak cooling load using building thermal mass and demonstrated that their proposed method can results in about 30\% reduction in peak cooling loads for the building they examined. Applications of building thermal energy storage have also been investigated as a strategy to shift peak building thermal loads [6 - 9]. Rabi and Norford [10] studied thermostat control strategies to reduce cooling load during the peak period by sub cooling a building during night time.

A variety of techniques used to reduce overall building energy consumption have been explored by several researchers. For example, Yang and Li [11] performed a quantitative analysis to reduce cooling load using thermal mass, night ventilation, and building time constant information. They reported that an increase of the time constant could reduce the cooling load by $60 \%$ when the time constant is more than 400 hours. Various building energy components, such as green and vegetation roofs [12 - 14], insulation material [15,16], and windows [17,18], have been considered to decrease thermal loads in buildings. Sadineni et al. [19] provided a detailed review of the building envelope components and their respective improvements from an energy efficiency perspective. Different types of energy efficient walls (trombe walls, ventilated walls, and glazed walls), fenestration technologies (aerogel, vacuum glazing and frames), energy efficient roofs (contemporary green roofs, photovoltaic roofs, radiant transmittive barrier, and evaporative roof cooling systems), various types of thermal insulation materials, and the effects of thermal mass and phase change material on building cooling/heating loads and peak loads were discussed in their review. Radiant

\footnotetext{
* Address correspondence to this author at the Department of Mechanical Engineering, Mississippi State University, Mississippi State, MS 39762, USA; Tel: 662-325-3260; Fax: 662-325-7223; E-mail: mago@me.msstate.edu
} 
heating and cooling technologies have been used to reduce building energy consumption [20, 21]. Several authors such as Feustel et al. [22], Venkoa et al. [23], Yin et al. [24], Tian and Love [25], Miriel et al. [26], Sanusi et al. [27], among others have investigated the implementation and use of radiant cooling and heating systems. Feustal et al. [22] performed a preliminary assessment indicating that radiant cooling has the potential to reduce peak power requirements, and hence, the total energy usage for cooling. Furthermore, Venkoa et al. [23] presented an experimental study on mixed convection with a cooled vertical wall and found that mixed convection improves effectiveness of radiant systems. Yin et al. [24] conducted an investigation on performance and condensation of radiant cooling panels and showed that, with proper control strategies, radiant cooling can be implemented in an effective manner while avoiding condensation. Tian and Love [25] showed that a radiant floor system combined with a conventional air conditioning system could reduce a dwelling's energy usage up to $80 \%$. Miriel et al. [26] studied the use of radiant systems in Europe and found that a minimum temperature of $17^{\circ} \mathrm{C}$ needs to be maintained to avoid condensation and that energy usage is reduced by $10 \%$. Sanusi et al. [27] examined a radiant system that uses the ground as a heat sink as method for achieving cooling in low energy buildings. Chowdhury et al. [28] explained that, in subtropical climates, a radiant system is a better alternative than pre cooling or the use of economizers in conventional cooling systems. Imanari et al. [29] found that, in Tokyo, a radiant cooling panel can reduce energy consumption by up to $10 \%$. Sattari and Farhanieh [30] presented a parametric study on radiant floor heating using finite element analysis and found that the type and thickness of the cover are the most important design parameters. Zhao et al. [31] found that a radiant floor cooling system can provide better thermal comfort and reduce energy demand by 20-30\% when compared to a conventional all air system. Fenget al. [32] found that the total cooling energy of radiant systems is 5-15\% higher than air systems. Oxizidis and Papadopoulos [33] determined that radiant cooling systems are most suitable for buildings with cooling loads generated mostly by solar or internal heat loads.

In contrast with radiant cooling or heating systems, Carpenter et al. [34] presented an analysis of using increased thermal capacitance (ITC) for passive energy management and showed that their proposed ITC systems has the potential to reduce the building cooling load. The main concept of ITC is to reduce building thermal load by circulating water through a piping system located in the building walls or ceiling. The reduction of the thermal load is achieved by increasing the effective thermal capacitance at selected surfaces of the building, e.g., ceiling and walls.Water is circulated through pipes embedded in these surfaces and routed through a large storage tank in order to achieve the same effect of a massive thermal capacitance. The focus of this paper is to evaluate the influence of several parameters on the potential of using ITC as a passive energy management system to decrease the building cooling load by circulating water from a storage tank through a piping system located in the building's ceiling. The cooling load of the ITC enhanced building is compared to the cooling load of a reference building without any form of ITC. Parameters that affect the performance of the ITC, including tank size, specific heat of the working fluid, mass flow rate of the working fluid, initial temperature of the working fluid, the pipe material, pipe wall thickness, and location of pipe in the roof are analyzed.The best results obtained by modifying the ITC performance parameters for each of the climate conditions investigated.

\section{DESCRIPTION OF THE SIMULATION ENVIRONMENT}

TRNSYS [35], a simulation program used in the fields of building simulation and thermal energy engineering, was used to model both the reference building and the building with ITC.The model generated in TRNSYS for the reference building is shown in Fig. (1). The weather information used to estimate the heating and cooling loads for the reference building is obtained from the Typical Meteorological Year (TMY) data derived from the National Solar Radiation Data Base (NSRDB) archives [36]. The reference building was modeled using the Type 56 Multizone Building component in TRNSYS. The mathematical model of the components can be found in [37].Once the baseline cooling and heating loads were found, the reference building was modified to include the proposed ITC in the ceiling. This location was selected based on the results presented by Carpenter et al. [34], which favored locating the ITC in the ceiling rather than in the walls. Fig. (2) illustrates the dynamic model with the ITC added in the ceiling. For this case, a piping system was inserted into the ceiling to increase the thermal capacitance. The piping system was placed between the inner and outer layers of the ceiling. Fluid circulating in the pipes allows the addition or removal of energy to or from the zone depending on temperatures of the fluid, zone air, and ambient air. The interior and exterior wall surface temperatures are calculated based on the effect of conduction between pipes and construction material using a two dimensional conduction analysis. For simulation of the ITC system, the proposed model adds to the reference model a storage tank component and a pump component to circulate water through the loop consisting of piping at the ceiling and the storage tank. The pump component chosen was a single speed pump. The storage tank component selected was a thermally 
insulated vertical storage tank with a single inlet as well as a single outlet. The storage tank was located outside the building and exposed to ambient weather conditions.

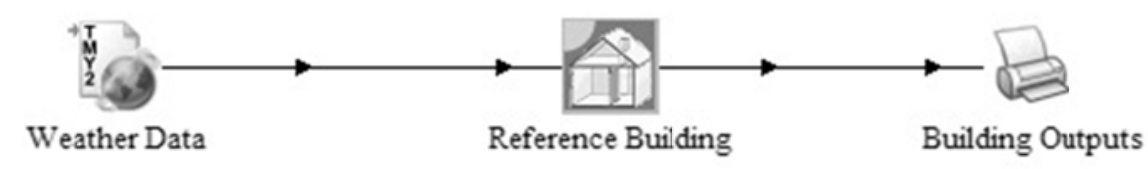

Fig. (1). Reference building model in TRNSYS.

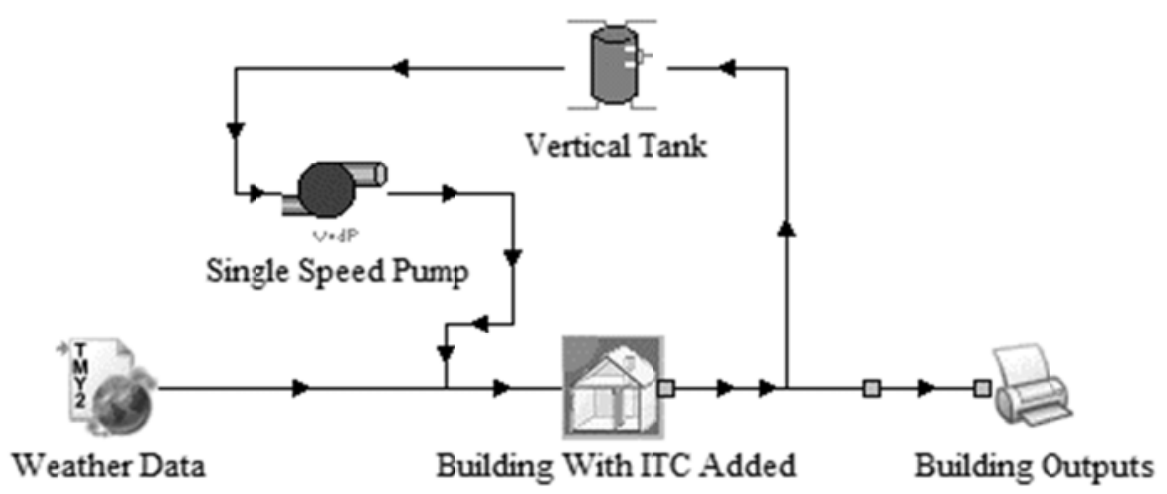

Fig. (2). Schematic of the TRNSYS model with ITC in the ceiling.

\section{RESULTS}

This section presents the results obtained using the models described in Section 2. First, a simulation of the reference building was used to determine the building's cooling load. Then, the same reference building with ITC implemented through the ceiling was simulated to determine the benefits from this passive energy management technique. After the benefits were established, the effects of several parameters on the performance of the ITC implementation were evaluated.These parameters included: the pipe material, pipe wall thickness, location of pipe in the ceiling, and the specific heat of the working fluid.

\subsection{Reference Building}

The reference building chosen was a hypothetical square office building with a surface area of $196 \mathrm{~m}^{2}(14 \mathrm{~m} \times 14$ $\mathrm{m}$ ), a wall height of $3.048 \mathrm{~m}$, a flat roof, and windows occupying $20 \%$ of the wall space. The building size is typical of a small office building.In this analysis the cooling thermal set point was set to $24^{\circ} \mathrm{C}$. The lighting power density was assumed to be $19 \mathrm{~W} / \mathrm{m}^{2}$, with the lights scheduled to turn on at $8 \mathrm{AM}$ and switch off at $5 \mathrm{PM}$. The simulation included 14 occupants working a nine hour day from 8 AM to $5 \mathrm{PM}$ on computers with a power density of $16.146 \mathrm{~W} / \mathrm{m}^{2}$. On the weekends the building is unoccupied and everything is shut off. The internal gains for lighting, occupants, and office equipment were estimated using [38]. The material properties for the walls, roof, and floor are presented in Tables 1-3, respectively. The initial reference building was simulated using weather data for Atlanta, GA.Since the main objective of the paper is to reduce the building's cooling load, the warmest months of the year, i.e., April through September, were used for the simulation.

Table 1. Building materials for the wall.

\begin{tabular}{|c|c|c|c|c|}
\hline Material & Thickness (m) & Conductivity $\mathbf{( W / m} \cdot \mathbf{K})$ & Capacity $(\mathbf{k J} / \mathbf{k g} \cdot \mathbf{K})$ & Density $\left(\mathbf{k g} / \mathbf{m}^{\mathbf{3}}\right)$ \\
\hline Gypsum Wall Board & 0.016 & 0.728 & 0.75 & 1601 \\
\hline Fiber Glass Insulation & 0.160 & 0.044 & 0.75 & 32 \\
\hline Gypsum Wall Board & 0.016 & 0.728 & 0.75 & 1601 \\
\hline Stucco & 0.025 & 0.692 & 0.75 & 1858 \\
\hline
\end{tabular}


Table 2. Building Materials for the roof.

\begin{tabular}{|c|c|c|c|c|}
\hline Material & Thickness $(\mathbf{m})$ & Conductivity $(\mathbf{W} / \mathbf{m} \cdot \mathbf{K})$ & Capacity $(\mathbf{k J} / \mathbf{k g} \cdot \mathbf{K})$ & Density $\left(\mathbf{k g} / \mathbf{m}^{\mathbf{3}}\right)$ \\
\hline Plaster Board & 0.016 & 0.528 & 0.84 & 1200 \\
\hline Fiber Glass Insulation & 0.160 & 0.044 & 0.75 & 32 \\
\hline Concrete & 0.102 & 1.731 & 0.75 & 2242 \\
\hline Roof Decking & 0.006 & 0.694 & 1 & 2100 \\
\hline
\end{tabular}

Table 3. Building materials for the floor.

\begin{tabular}{|c|c|c|c|c|}
\hline Material & Thickness (m) & Conductivity $(\mathbf{W} / \mathbf{m} \cdot \mathbf{K})$ & Capacity $(\mathbf{k J} / \mathbf{k g} \cdot \mathbf{K})$ & Density $\left(\mathbf{k g} / \mathbf{m}^{\mathbf{3}}\right)$ \\
\hline Stone & 0.025 & 1.436 & 1.5 & 881 \\
\hline Fiber Glass Insulation & 0.076 & 0.044 & 0.75 & 32 \\
\hline Concrete & 0.102 & 1.731 & 0.75 & 2242 \\
\hline
\end{tabular}

Fig. (3) displays the cooling load estimated in TRNSYS, along with the indoor zone temperature and ambient temperature for the first week in May, with a week time period chosen so the temperature profiles could clearly be appreciated. As is shown in Fig. (3), the cooling load varies with the ambient temperature while the indoor zone temperature remains around $24^{\circ} \mathrm{C}$ throughout the day and drops at night.

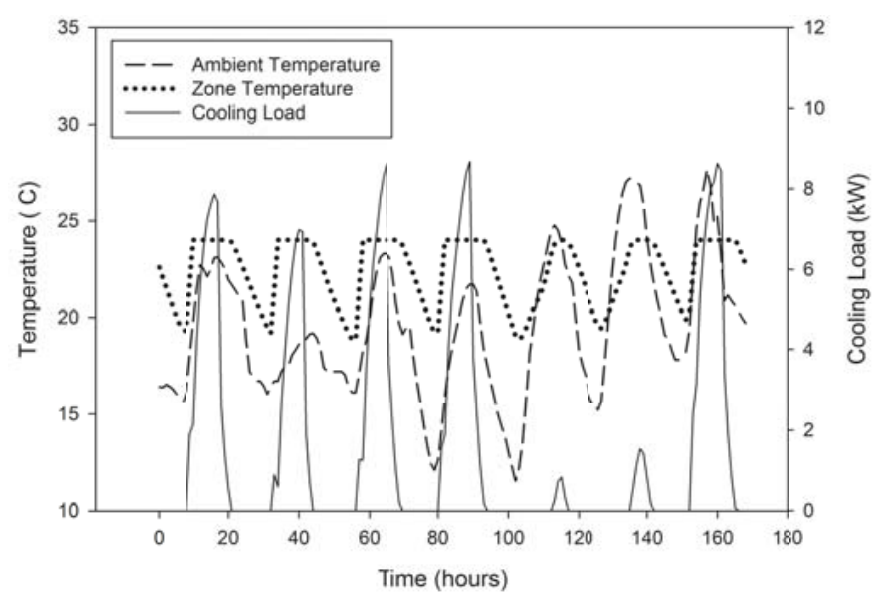

Fig. (3). Reference building cooling load, ambient and zone temperature for a week in May.

\subsection{ITC Added to the Ceiling}

This section compares the reference building described in Section 3.1 (Case 1) with a similar configuration, but implementing an ITC by placing a circulating fluid piping loop in the insulation layer of the ceiling (Case 2). For Case 2 , the mass flow rate of the circulating fluid was selected at $500 \mathrm{~kg} / \mathrm{h}$ between $6 \mathrm{AM}$ and $8 \mathrm{PM}$ and then the system was shutdown through the night from 8PM to 6 AM.A storage tank size of $7.571 \mathrm{~m}^{3}$ (2,000 gal), and an initial working fluid temperature of $20^{\circ} \mathrm{C}$ were used. Table 4 shows the information of the piping system used to simulate Case 2 . For this case, the piping system was positioned at the center of the insulation layer in the ceiling. Fig. (4) presents a comparison of the cooling load required for a week in May between Case 1 and Case 2. Similar to Fig. (3), a week time period was chosen so the temperature profiles could clearly be appreciated. Fig. (4) illustrates that the peak cooling load for each day of the selected week is reduced with the implementation of the ITC system through the ceiling. For example, the total cooling load for the month of May was reduced by $5.9 \%$ with the addition of ITC. The energy required for pumping the working fluid is included in the net cooling load calculations. By reducing the amount of energy needed for cooling the associated net operating cost is also reduced.

Table 4. Piping system specifications.

\begin{tabular}{|c|c|c|c|c|c|}
\hline Pipe Material & Pipe Spacing (m) & Outside Diameter (m) & Pipe Wall Thickness (m) & Conductivity $(\mathbf{W} / \mathbf{m} \cdot \mathbf{K})$ & $\mathbf{C}_{\mathbf{p}}$ of Water $(\mathbf{k J} / \mathbf{k g} \cdot \mathbf{K})$ \\
\hline Cooper & 0.2 & 0.0182 & 0.00277 & 401 & 4.18 \\
\hline
\end{tabular}




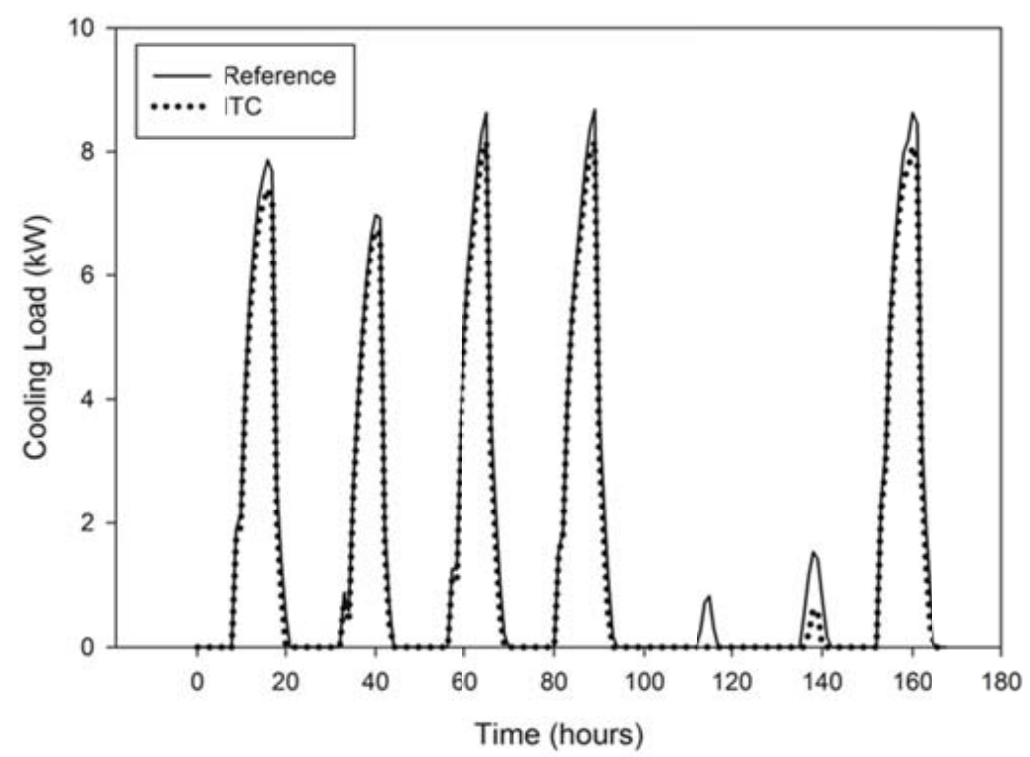

Fig. (4). Cooling load comparison for a week in May for the two cases evaluated in this paper.

Fig. (5) shows a month by month reduction for the entire simulation. The reduction for each month decreases as the outdoor temperatures increase. The highest reduction was obtained for the month of April, about $7 \%$, while the lowest was obtained for August, about 2.9\%.It seems that the potential reduction of the building's cooling load is strongly dominated by the outdoor temperature profile.

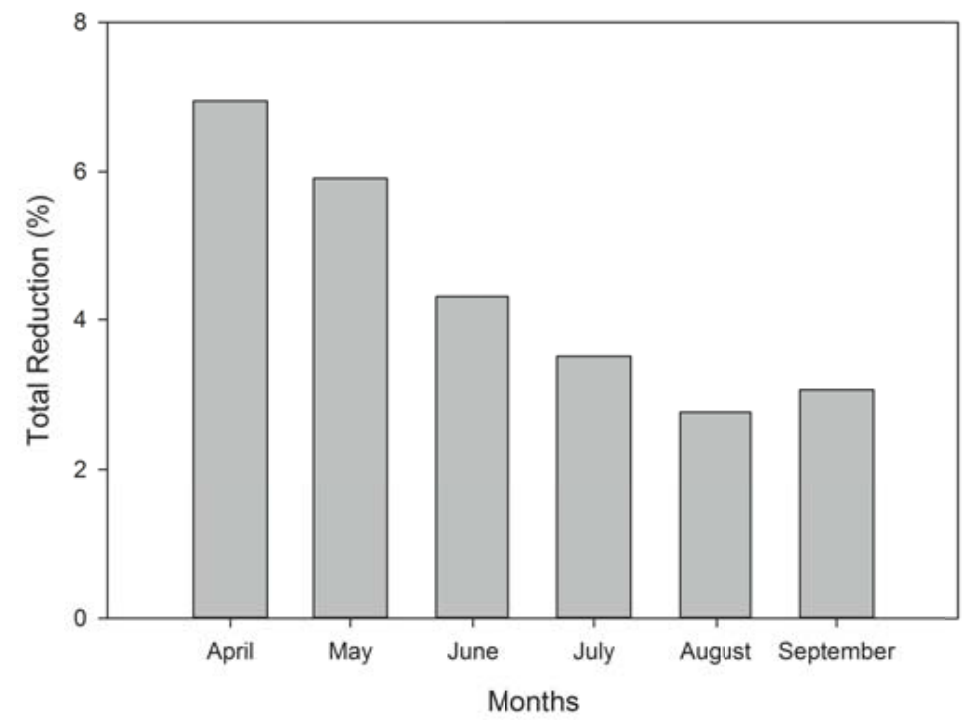

Fig. (5). Month by month reduction with use of ITC in Atlanta.

\subsection{Effect of Different Parameters on the Overall Performance of the ITC}

This section considers the sensitivity of different parameters on the benefits of using ITC to reduce the cooling load of a building. The parameters considered are: climate conditions, storage tank volume, specific heat, mass flow rate, and initial temperature of the working fluid, pipe material (thermal conductivity), pipe wall thickness, and location of the piping system in the ceiling.

\subsubsection{Climate Conditions}

The first parameter to be analyzed is the effect of the geographical location of the building, which affects the climate conditions on the ITC performance. Four locations, with different climate conditions, were analyzed in this 
paper: Atlanta, GA, San Diego, CA, New York, NY, and Phoenix, AZ.With the exception of the weather data, all other parameters remained at the nominal values described in Section 3.2. Fig. (6) shows a month by month reduction for each city from April to September. All cities follow a similar pattern, with more benefits obtained in April than in August and September. San Diego shows the most consistent reduction per month. This is due to the fact that the outdoor temperature does not change significantly in this location for the selected months. For the other three locations, the benefits from ITC decrease for the hotter months (July, August, and September). For these locations, the outdoor temperature significantly change from April to September, which strongly affects the potential of the proposed system to reduce the building cooling load.

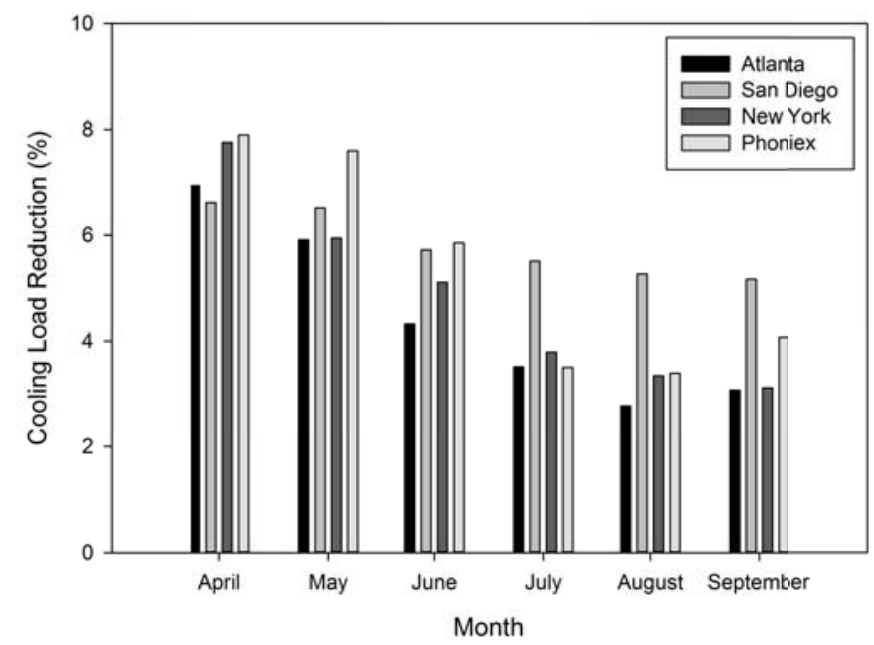

Fig. (6). Effect of geographical location on ITC.

\subsubsection{Storage Tank Size}

The next parameter to be analyzed is the volume of the storage tank, i.e., the amount of thermal capacitance. For this analysis tank sizes of $3.785 \mathrm{~m}^{3}$ (1,000 gal), $7.571 \mathrm{~m}^{3}$ (2,000 gal), and $11.356 \mathrm{~m}^{3}$ (3,000 gal) were used. Fig. (7) shows the total cooling load reduction for each month of the analysis. As shown in Fig. (7), the larger tank size increased the total cooling load reduction for each month. For example, for the month of April, the cooling load reduction went from $5.1 \%$ for the smallest tank to about $8 \%$ for the largest tank. This can be explained since by increasing the storage tank size, the total thermal capacitance of the system is increased, which allows more energy to be removed from the building.

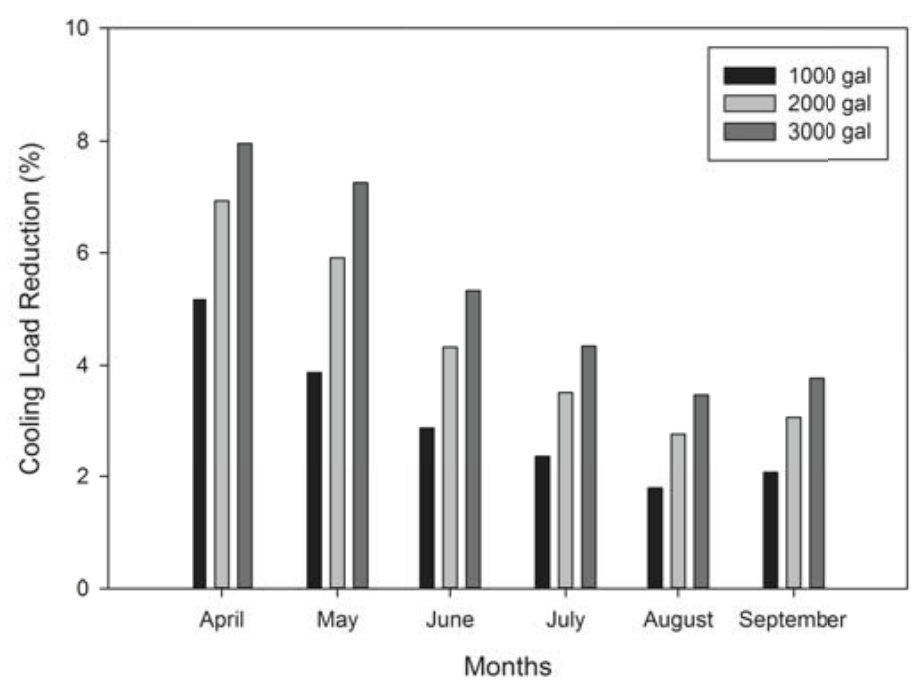

Fig. (7). Effect of storage tank size on the performance of ITC. 


\subsubsection{Specific Heat of the Working Fluid}

The next parameter to be analyzed is the type of working fluid used in the ITC. In this paper, this is evaluated by varying the specific heat of the working fluid to determine the effect on the ITC performance. By increasing the specific heat of the working fluid, the total capacitance of the ITC should increase. The specific heat is varied from $4.18 \mathrm{~kJ} / \mathrm{kg} \cdot \mathrm{K}$ (specific heat of water) to $10 \mathrm{~kJ} / \mathrm{kg} \cdot \mathrm{K}$. The other parameters were kept the same as described in Section 3.2. Fig. (8) shows the cooling load reduction based on the specific heat of the working fluid for the months of April through September.The results indicate that as the specific heat of the working fluid increases the amount of cooling load required decreases. This could be explained by the role of specific heat on the thermal capacitance, i.e. as the specific heat rises the thermal capacitance increases.

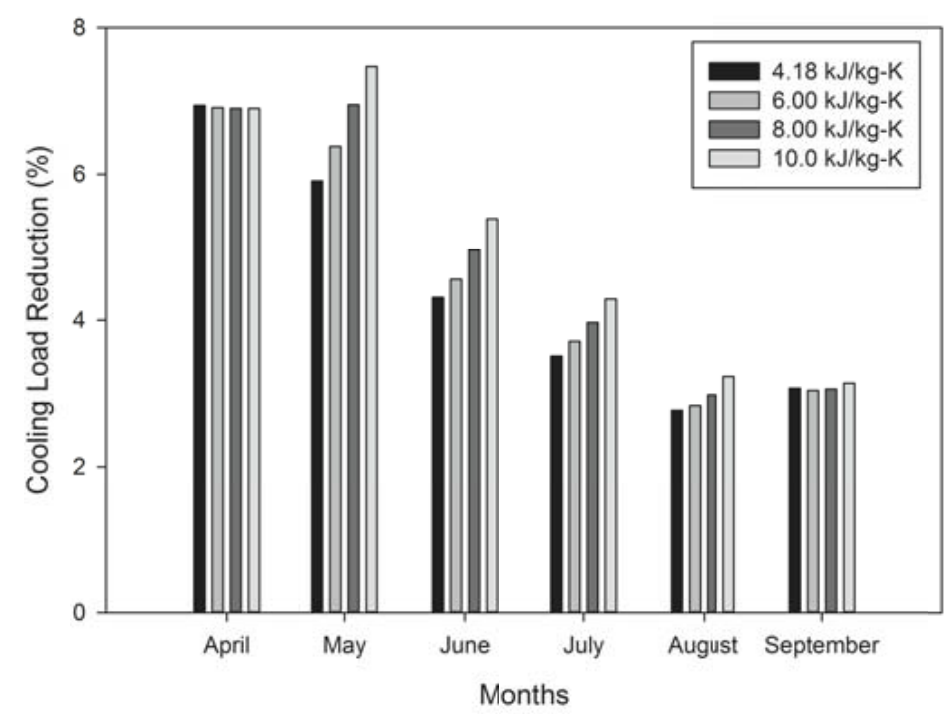

Fig. (8). Effect of working fluid's specific heat on performance of ITC.

\subsubsection{Mass Flow Rate}

The next parameter to be analyzed is the mass flow rate of the working fluid. The mass flow rate decreases the resistance to heat flow in or out of the ITC. The mass flow rates were set at $250 \mathrm{~kg} / \mathrm{hr}, 500 \mathrm{~kg} / \mathrm{hr}$, and $750 \mathrm{~kg} / \mathrm{hr}$, with all other parameters kept the same as described in Section 3.2. Fig. (9) shows the month by month cooling load reduction based upon the mass flow rate.

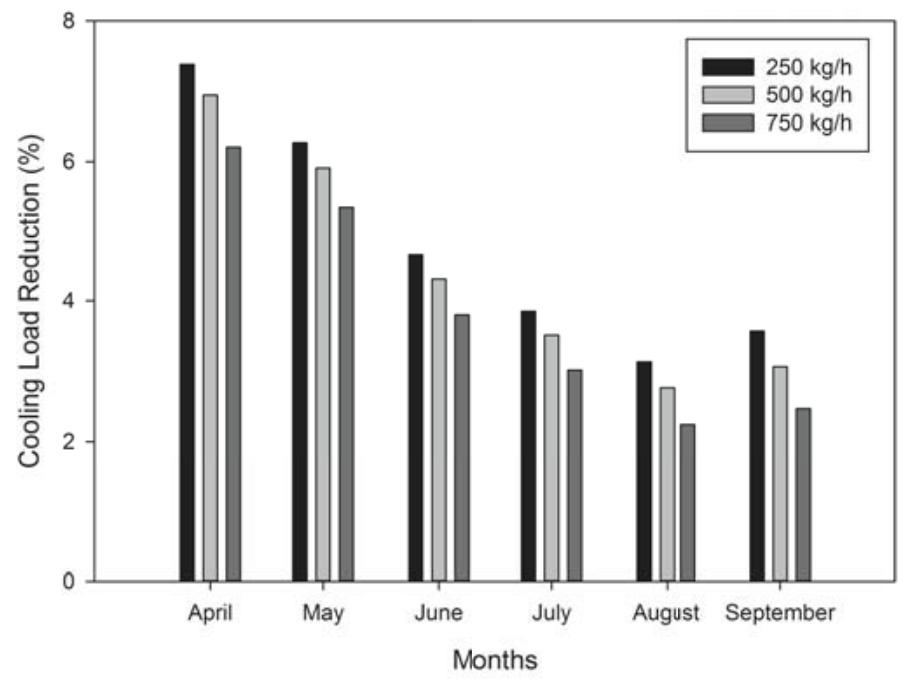

Fig. (9). Effect of working fluid's mass flow rate on performance of ITC. 
Results indicate that, as the mass flow rate increases, the total reduction per month decreases. For example, for the month of April, for the lowest mass flow rate the reduction was $7.5 \%$ while for the highest mass flow rate was about $6 \%$.This may be explained by considering that the extra pumping power required to increase the flow rate outweighs the extra benefits of increasing the flow rate.

\subsubsection{Pipe Material}

The next parameter to be analyzed is the thermal conductivity of the pipes. A higher thermal conductivity should increase the amount of energy added or removed from the building. The thermal conductivity was varied between 1 $\mathrm{W} / \mathrm{m} \cdot \mathrm{K}$, which is close to the thermal conductivity of PVC, and $400 \mathrm{~W} / \mathrm{m} \cdot \mathrm{K}$, which is close to the thermal conductivity of cooper. All other parameters were kept the same as described in Section 3.2. Fig. (10) shows the amount of cooling load reduction due to thermal conductivity for the months of April through June. Results indicate that the thermal conductivity of the pipes does not have a strong influence on the ITC performance and therefore on the total cooling load reduction. The small amount of change based on thermal conductivity is due to the insulation's thermal resistance being much larger than the piping's thermal resistance. The insulation's thermal resistance is approximately 10 times greater than the piping's thermal resistance, thus the greatest temperature difference is through the insulation layers. This causes the temperature distribution through the piping layer to be similar with regards to piping material. This is similar to the results presented by Sattari and Farhanieh [30].

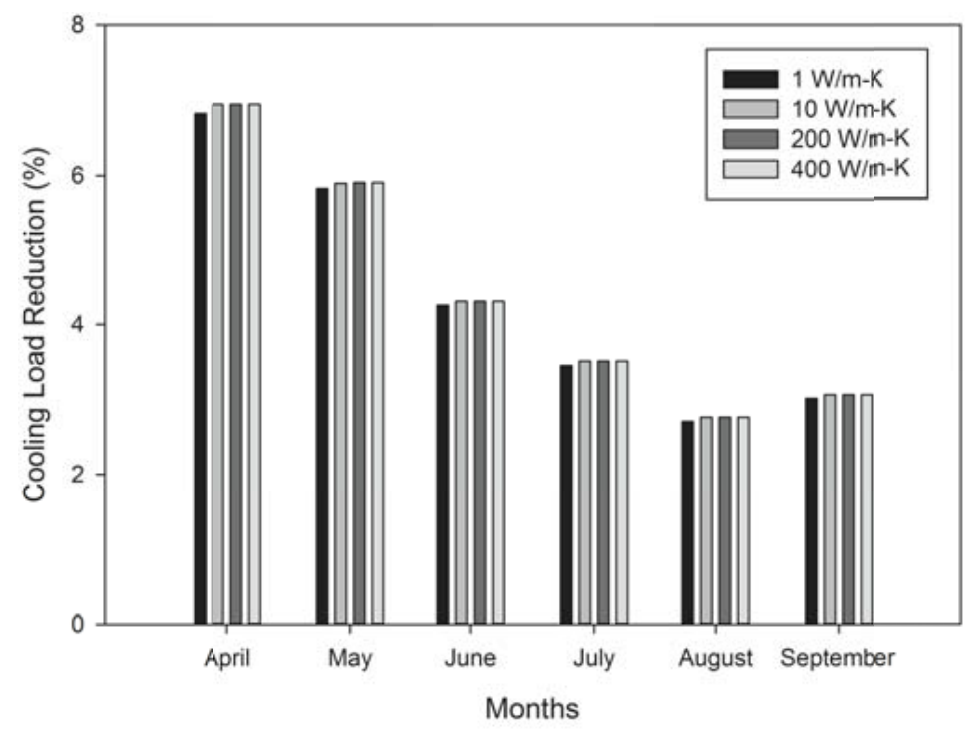

Fig. (10). Effect of pipe's thermal conductivity on performance of ITC.

\subsubsection{Pipe Wall Thickness}

The next parameter to be analyzed is the pipe wall thickness by varying the outer diameter of the pipes. Pipe wall thickness increases the resistance of heat flow into or out of the ITC. The wall thickness was varied from $0.0021 \mathrm{~m}$ to $0.0037 \mathrm{~m}$. Similar to the previous cases the values of the other parameters were kept the same as described in Section 3.2. Fig. (11) shows the cooling load reduction based on pipe wall thickness for the months of April through September. As can be seen in Fig. (12) the potential to decrease the cooling load increases linearly with increasing the pipe wall thickness. The critical radius can be used to explain, where the inner radius is smaller than critical radius of conduction to convection. This causes a reduction in the total thermal resistance so that the heat transfer rate increases with a larger pipe wall thickness.

\subsubsection{Location of the ITC in the Ceiling}

The final parameter analyzed is the location of the ITC layer in the ceiling. By changing the location of the piping system, inside the insulation layer, more heat can be drawn from either inside the house or outside the house. The location of the piping system inside the insulation is shown in Fig. (12). In Fig. (12a) the piping system is closer to the exterior, in Fig. (12b) the piping system is in the center and in Fig. (12c) the piping system is closer to the interior. The 
values of the other parameters were the same as described in Section 3.2. Fig. (13) shows the cooling load reduction based on pipe location in the insulation layer for the month of May. Results indicate that locating the piping system closer to the interior of the building provides more benefits in terms of cooling load reduction. When the piping system is located closer to the interior, the exterior insulation is able to provide more resistance to the outside and the piping system is able to remove more energy from the building. This maintains a lower fluid temperature in the ITC, which allows the ITC to provide more benefits throughout the evaluated month.

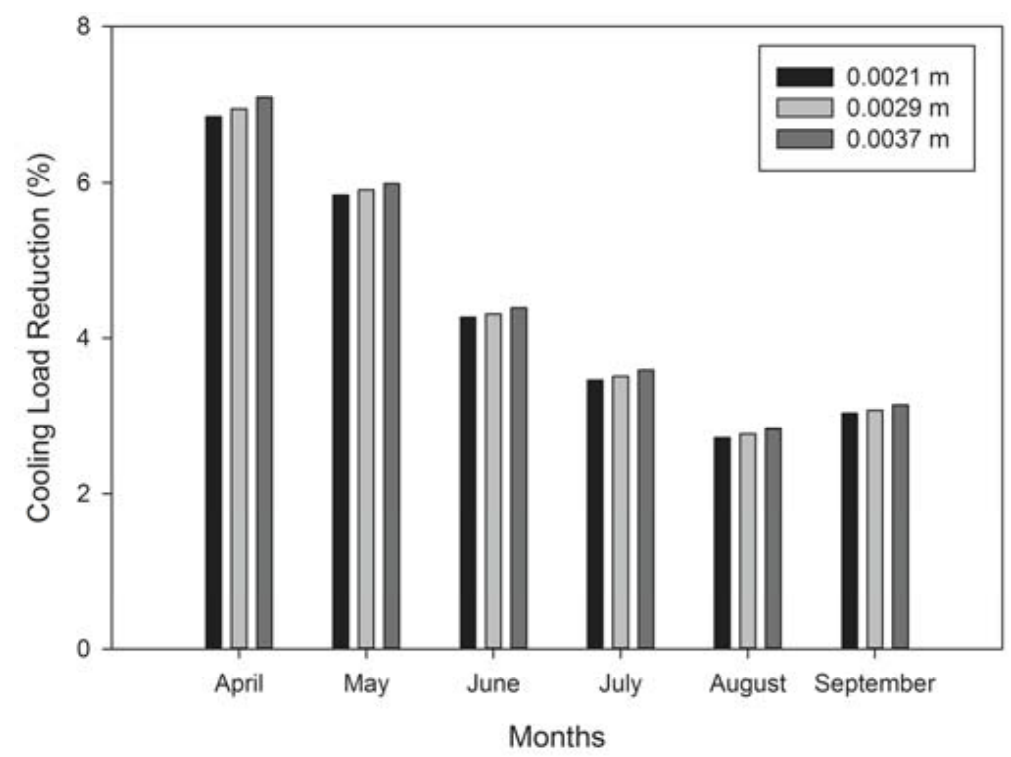

Fig. (11). Effect of pipe wall thickness on performance of ITC.

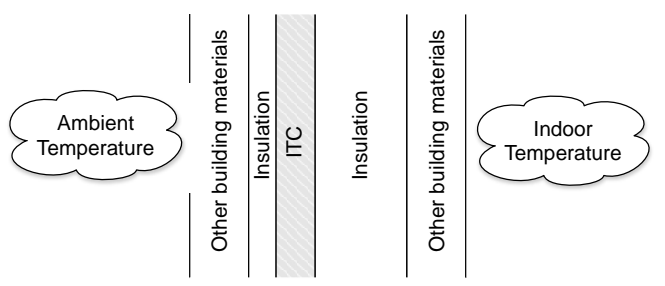

(a)

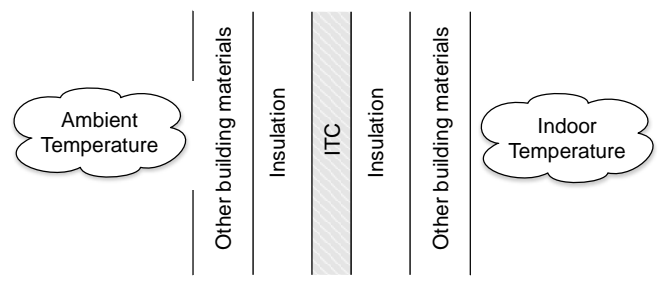

(b)

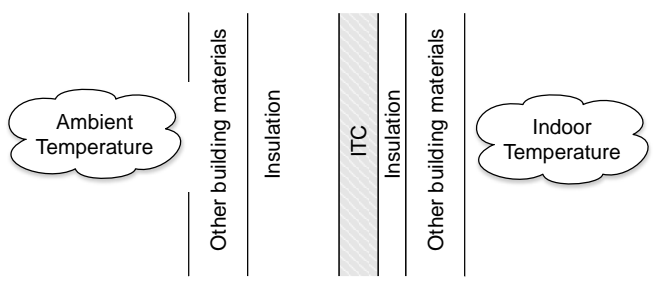

(c)

Fig. (12). Model of location of pipe in insulation layer. 


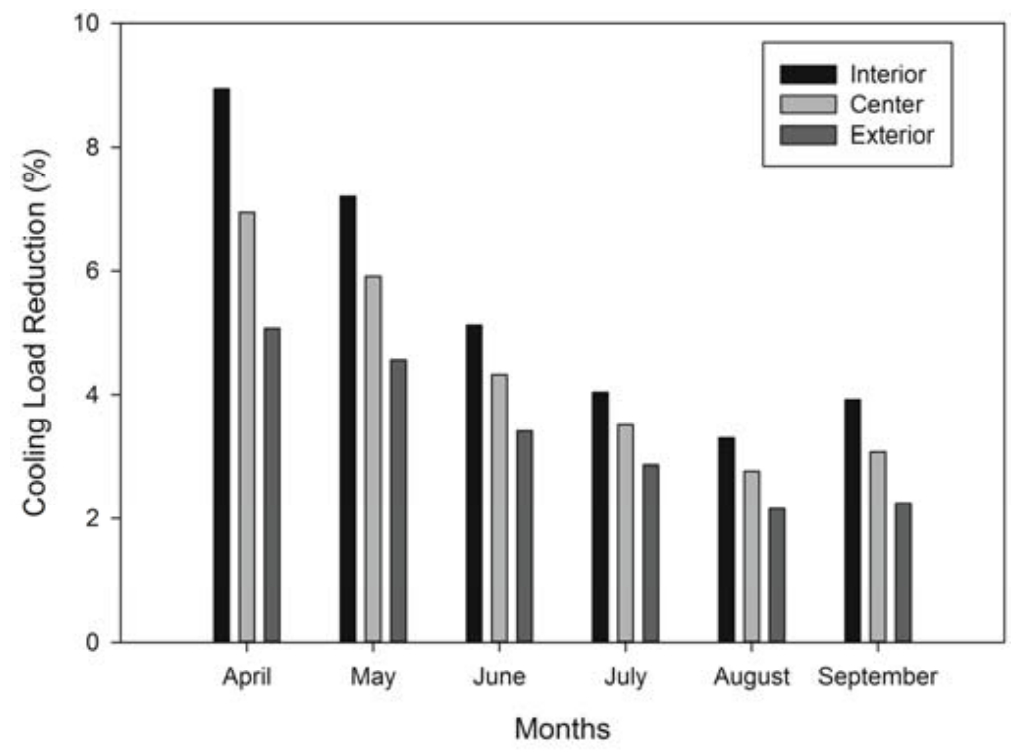

Fig. (13). Effect of pipe location within roof on performance of ITC.

\subsection{ITC Optimized in Four Geographical Locations}

This section presents the results for optimizing the parameters to get the best results possible from the ITC implementation. For this analysis water was used as the working fluid with a specific heat of $4.18 \mathrm{~kJ} / \mathrm{kg} \cdot \mathrm{K}$, while all other parameters were optimized for the best results. The pipe was located at closer to the interior with a thermal conductivity of $400 \mathrm{~W} / \mathrm{m} \cdot \mathrm{K}$ with a pipe thickness of $0.0037 \mathrm{~m}$. The mass flow rate of the fluid was $250 \mathrm{~kg} / \mathrm{hr}$ with an initial water temperature of $18^{\circ} \mathrm{C}$ and tank size of $11.356 \mathrm{~m}^{3}(3,000$ gal) were used. For this analysis all four geographical location were analyzed with the month by month results shown in Fig. (14). As is shown in Fig. (14) the pattern is similar to the results presented in Section 3.3.1 with the reduction for each month being greater. The overall reduction for each city increased by over $2 \%$ with the optimized system. Reductions of more than $10 \%$ were obtained for all locations for the month of April. San Diego is the city that presents the best performance in terms of average reduction (about 9\%).

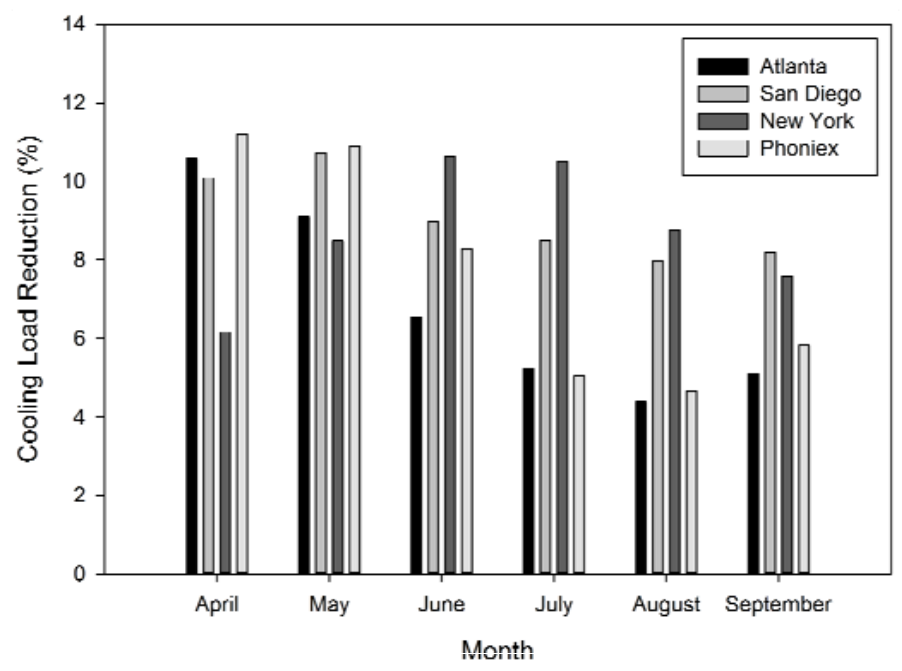

Fig. (14). Optimization of the performance of ITC.

\section{CONCLUSION}

This paper examined the effect of several parameters on the benefits of using ITC as a passive energy management 
system to reduce the cooling load of buildings. A reference building was simulated in Atlanta, GA for the months of April through September to get a base cooling load for comparison. An ITC system was then added to the reference building and simulated to verify that the ITC system was able to reduce the cooling load. Several key parameters, such as tank size, specific heat, mass flow rate, and initial temperature of the working fluid, pipe thermal conductivity, pipe wall thickness, and pipe location in ceiling were analyzed to assess the influence of each parameter on the performance of the ITC. Results indicated that ITC is useful in all parts of the country. In addition,ITC shows more potential in locations where the outside temperature does not have a significant change from April to September such as the climate conditions in San Diego.The ITC system is able to provide reductions between $6.5 \%$ to $5 \%$ in this city for the evaluated months. On the other hand, in cities where the outdoor temperature significantly change between April in September, results indicated that tank size and specific heat of the working fluid have the greatest effects on the ability of the ITC to reduce the cooling load. The parameter analysis also showed that the initial working fluid temperature, piping thickness, and piping thermal conductivity do not have a strong influence on the benefits that could be obtained from the ITC application for the reduction of the cooling load. However, the location of the piping system within the insulation layer and mass flow rate of the working fluid are parameters that have some influence on the ability of the ITC to reduce the cooling load. By optimizing these parameters, the total cooling load in each city was increased by over $2 \%$.Further research is needed in improving the effectiveness of the ITC along with detailed analysis of cost. Also research is needed for using ITC in cooler months for heating.

\section{CONFLICT OF INTEREST}

The authors confirm that this article content has no conflict of interest.

\section{ACKNOWLEDGEMENTS}

Declared none.

\section{REFERENCES}

[1] U.S. Department of Energy, "Energy Information Administration", Heating and cooling no longer majority of U.S. home energy use, U.S. Department of Energy, 2013.. Available from: http://www.eia.gov Accessed on: [7 March 2013].

[2] P. Palensky, and D. Dietrich, "Demand side management: demand response, intelligent energy systems, and smart loads", Indus. Inform. IEEE Trans. on, vol. 7, no. 3, pp. 381-388, 2011 [http://dx.doi.org/10.1109/TII.2011.2158841]

[3] D.S. Loughran, and J. Kulick, "Demand-side management and energy efficiency in the United States", J. Energy, vol. 25, no. 1, pp. 19-43, 2004.

[4] G. Strbac, "Demand side management: benefits and challenges", Energy Policy, vol. 36, no. 12, pp. 4419-4426, 2008. [http://dx.doi.org/10.1016/j.enpol.2008.09.030]

[5] K. Lee, and J.E. Braun, "Model-based demand limiting control of building thermal mass", Build. Environ., vol. 43, no. 10, pp. 1633-1646, 2008 .

[http://dx.doi.org/10.1016/j.buildenv.2007.10.009]

[6] Y. Zhang, G. Zhou, K. Lin, Q. Zhang, and H. Di, "Application of latent heat thermal energy storage in buildings: state-of-the-art and outlook", Build. Environ., vol. 42, no. 6, pp. 2197-2209, 2007. [http://dx.doi.org/10.1016/j.buildenv.2006.07.023]

[7] G.P. Henze, C. Felsmann, and G. Knabe, "Evaluation of optimal control for active and passive building thermal storage", Int. J. Therm. Sci., vol. 43, no. 2, pp. 173-183, 2004.

[http://dx.doi.org/10.1016/j.ijthermalsci.2003.06.001]

[8] V.V. Tyagi, and D. Buddhi, "PCM thermal storage in buildings: A state of art", Renew. Sustain. Energy Rev., vol. 11, no. 6, pp. 1146-1166, 2007.

[http://dx.doi.org/10.1016/j.rser.2005.10.002]

[9] T.A. Reddy, L.K. Norford, and W. Kempton, "Shaving residential air conditioner electricity peaks by intelligent use of the building thermal mass", Energy, vol. 16, no. 7, pp. 1001-1010, 1991.

[http://dx.doi.org/10.1016/0360-5442(91)90060-Y]

[10] A. Rabl, and L.K. Norford, "Peak load reduction by preconditioning buildings at night", Int. J. Energy Res., vol. 15, no. 9, pp. 781-798, 1991. [http://dx.doi.org/10.1002/er.4440150909]

[11] L. Yang, and Y. Li, "Cooling load reduction by using thermal mass and night ventilation", Energy Build., vol. 40, no. 11, pp. 2052-2058, 2008 .

[http://dx.doi.org/10.1016/j.enbuild.2008.05.014] 
[12] M. Santamouris, C. Pavlou, P. Doukas, G. Mihalakakou, A. Synnefa, A. Hatzibiros, and P. Patargias, "Investigating and analysing the energy and environmental performance of an experimental green roof system installed in a nursery school building in Athens, Greece", Energy, vol. 32, no. 9, pp. 1781-1788, 2007. [http://dx.doi.org/10.1016/j.energy.2006.11.011]

[13] A. Niachou, K. Papakonstantinou, M. Santamouris, A. Tsangrassoulis, and G. Mihalakakou, "Analysis of the green roof thermal properties and investigation of its energy performance", Energy Build., vol. 33, no. 7, pp. 719-729, 2001. [http://dx.doi.org/10.1016/S0378-7788(01)00062-7]

[14] R. Kumar, and S.C. Kaushik, "Performance evaluation of green roof and shading for thermal protection of buildings", Build. Environ., vol. 40, no. 11, pp. 1505-1511, 2005. [http://dx.doi.org/10.1016/j.buildenv.2004.11.015]

[15] K.A. Antonopoulos, and E.P. Koronaki, "Thermal parameter components of building envelope", Appl. Therm. Eng., vol. 20, no. 13, pp. 1193-1211, 2000.

[http://dx.doi.org/10.1016/S1359-4311(99)00090-3]

[16] D.M. Al-Homoud, "Performance characteristics and practical applications of common building thermal insulation materials", Build. Environ., vol. 40, no. 3, pp. 353-366, 2005. [http://dx.doi.org/10.1016/j.buildenv.2004.05.013]

[17] A.S. Bahaj, P.A. James, and M.F. Jentsch, "Potential of emerging glazing technologies for highly glazed buildings in hot arid climates", Energy Build., vol. 40, no. 5, pp. 720-731, 2008. [http://dx.doi.org/10.1016/j.enbuild.2007.05.006]

[18] W.N. Hien, W. Liping, A.N. Chandra, A.R. Pandey, and W. Xiaolin, "Effects of double glazed facade on energy consumption, thermal comfort and condensation for a typical office building in Singapore", Energy Build., vol. 37, no. 6, pp. 563-572, 2005. [http://dx.doi.org/10.1016/j.enbuild.2004.08.004]

[19] S.B. Sadineni, S. Madala, and R.F. Boehm, "Passive building energy savings: A review of building envelope components", Renew. Sustain. Energy Rev., vol. 15, no. 8, pp. 3617-3631, 2011. [http://dx.doi.org/10.1016/j.rser.2011.07.014]

[20] ASHRAE Handbook - HVAC Applications, American Society of Heating, Refrigerating, and Air-Conditioning Engineers.. ASHRAE: Atlanta, GA, 2011.

[21] Advanced Energy Design Guide for Small to Medium Office Buildings, American Society of Heating, Refrigerating, and Air-Conditioning Engineers.. ASHRAE: Atlanta, GA, 2011.

[22] H. Feustel, and C. Stetiu, "Hydronic radiant cooling-preliminary assessment", Energy Build., vol. 22, pp. 193-205, 1995. [http://dx.doi.org/10.1016/0378-7788(95)00922-K]

[23] S. Venkoa, D. Ventósa, C. Arkarb, and S. MedvedbaHidraia, "An experimental study of natural and mixed convection over cooled vertical room wall", Energy Build., vol. 68, pp. 387-395, 2014. [http://dx.doi.org/10.1016/j.enbuild.2013.09.014]

[24] Y. Yin, R. Wang, X. Zhai, and F. Ishugah, "Experimental investigation on the heat transfer performance and water condensation phenomenon of radiant cooling panels", Build. Environ., vol. 71, pp. 15-23, 2014. [http://dx.doi.org/10.1016/j.buildenv.2013.09.016]

[25] Z. Tian, and J. Love, "Energy performance optimization of radiant slab cooling using building simulation and field measurements", Energy Build., vol. 41, pp. 320-330, 2009

[http://dx.doi.org/10.1016/j.enbuild.2008.10.002]

[26] J. Miriel, L. Serres, and A. Trombe, "Radiant ceiling panel heating-cooling systems: experimental and simulated study of the performances, thermal comfort and energy consumptions", Appl. Therm. Eng., vol. 22, pp. 1861-1873, 2002. [http://dx.doi.org/10.1016/S1359-4311(02)00087-X]

[27] A. Sanusi, L. Shao, and N. Ibrahim, "Passive ground cooling system for low energy buildings in Malaysia (hot and humid climates)", Renew. Energy, vol. 49, pp. 193-196, 2013. [http://dx.doi.org/10.1016/j.renene.2012.01.033]

[28] A. Chowdhury, M. Rasul, and A. Khan, "Thermal comfort analysis and simulation for various low energy cooling techniques applied to an office building in a subtropical climate", Appl. Energy, vol. 85, pp. 449-462, 2008. [http://dx.doi.org/10.1016/j.apenergy.2007.10.001]

[29] T. Imanari, T. Omori, and K. Bogaki, "Thermal comfort and energy consumption of the radiant ceiling panel system. Comparison with the conventional all-air system", Energy Build., vol. 30, pp. 167-175, 1999. [http://dx.doi.org/10.1016/S0378-7788(98)00084-X]

[30] S. Sattari, and B. Farhanieh, "A parametric study on radiant floor heating system performance", Renew. Energy, vol. 31, pp. 1617-1626, 2006. [http://dx.doi.org/10.1016/j.renene.2005.09.009]

[31] K. Zhao, X. Liu, and Y. Jiang, "Application of radiant floor cooling in large open space building with high-intensity solar radiation", Energy Build., vol. 66, pp. 246-257, 2013. [http://dx.doi.org/10.1016/j.enbuild.2013.07.014] 
[32] J. Feng, S. Schiavon, and F. Bauman, "Cooling load differences between radiant and air systems", Energy Build., vol. 65, pp. 310-321, 2013. [http://dx.doi.org/10.1016/j.enbuild.2013.06.009]

[33] S. Oxizidis, and A.M. Papadopoulos, "Performance of radiant cooling surfaces with respect to energy consumption and thermal comfort", Energy Build., vol. 57, pp. 199-209, 2013.

[http://dx.doi.org/10.1016/j.enbuild.2012.10.047]

[34] J. Carpenter, P. Mago, R. Luck, and H. Cho, "Passive energy management through increased thermal capacitance", Energy Build., vol. 75, pp. 465-471, 2014. [http://dx.doi.org/10.1016/j.enbuild.2014.02.044]

[35] S.A. Klein, TRNSYS 17: A Transient System Simulation Program, Solar Energy Laboratory. University of Wisconsin: Madison, USA, 2010.

[36] U.S. Department of Energy. National Renewable Energy Laboratory, Brief., Summary (Indianap. Ind.), vol. TMY2s, .

[37] "TRNSYS 17. Mathematical Reference". Solar Energy Laboratory, University of Wisconsin, Madison, USA, Available from: http://sel.me.wisc.edu/trnsys Accessed on: [7 March 2013].

[38] A. Bell, HVAC Equations, Data, and Rules of Thumb., $2^{\text {nd }}$ ed The McGraw-Hill Companies, Inc., 2007.

Received: June 5, 2015

Revised: September 29, 2015

Accepted: September 30, 2015

(C) Carpenter et al.; Licensee Bentham Open.

This is an open access article licensed under the terms of the Creative Commons Attribution-Non-Commercial 4.0 International Public License (CC BY-NC 4.0) (https://creativecommons.org/licenses/by-nc/4.0/legalcode), which permits unrestricted, non-commercial use, distribution and reproduction in any medium, provided the work is properly cited. 